\title{
Comparison between Conventional Macintosh Laryngoscope and King Vision Video Laryngoscope in Endotracheal Intubation for Elective Surgeries: A Prospective Randomized Study
}

\author{
Shalaka R Sonavane ${ }^{1}$, Sunil K Gvalanil², Pratika P Bhokare ${ }^{3}$
}

\begin{abstract}
Introduction: Securing the airway with an endotracheal tube is an essential anesthesia skill. Despite improvements in intubation devices, tracheal intubation is still accomplished using the traditional method of direct laryngoscopy. ${ }^{1}$ The failure of direct laryngoscopy to provide an adequate glottic visualization, coupled with a major pressor response, has led to the development of newer intubation devices. Video laryngoscope is one such intubation device with advantages of a higher success rate, better glottic visualization, safer intubation, faster learning curve, and the opportunity for dynamic interaction during airway management. ${ }^{3}$ In our study, we have used King Vision Video Laryngoscope (KVVL) for tracheal intubation and compared its efficacy, ease, safety, and shorter learning curve with that of the conventional Macintosh direct laryngoscope. The laryngoscopic view, hemodynamic response, and the attempts and time of endotracheal intubation of both Macintosh and KVVL have been compared in this prospective randomized study.

Materials and methods: A total of 200 patients were assigned into two groups, I and II, where group I consists of patients receiving general anesthesia with endotracheal intubation using conventional Macintosh blade; and group II consists of patients receiving general anesthesia with endotracheal intubation using KVVL. Preoperative anesthesia check-ups and airway assessments were done which included mouth opening, MPC grading, and measurement of thyromental distance. The parameters studied were laryngoscopy view (using modified Cormack-Lehane scoring system), assessment of laryngoscopy and intubation procedure (number of attempts for successful intubation, maneuvers used during laryngoscopy, endotracheal tube insertion time), and hemodynamic response (heart rate, mean arterial blood pressure, and $\mathrm{SpO}_{2}$ ).

Results: The hemodynamic response to laryngoscopy and intubation was significantly lower with KVVL. Also, KVVL had superior glottic vision and less maneuver requirement during laryngoscopy.

Conclusion: From our study of comparison between Macintosh and KVVL, we conclude that KVVL is more effective in reducing hemodynamic response to intubation and requires less optimization maneuvers.

Clinical significance: This study aims at providing evidence to guide the anesthesiologists regarding the merits and demerits of video laryngoscopes and aid them in safer airway management techniques without complications.

Keywords: Intubation, King Vision, Macintosh, Pressor response, Prospective randomized study.

Research and Innovation in Anesthesia (2020): 10.5005/jp-journals-10049-0090
\end{abstract}

\section{INTRODUCTION}

Airway management is one of the essential skills in anesthesia for patient safety and to avoid anesthesia-related complications. Direct laryngoscopy has been the standard technique for tracheal intubation since its introduction in the early 19 th century. ${ }^{1}$ Laryngoscopy and tracheal intubation, however, are associated with hemodynamic changes; caused due to intense sympathetic discharge on stimulation of epipharynx and laryngopharynx. ${ }^{2}$

The failure of direct laryngoscopy to provide an adequate glottic visualization, coupled with a major pressor response, has led to the development of newer intubation devices. Video laryngoscope is one such intubation device with advantages of a higher success rate, better glottic visualization, safer intubation, faster learning curve, and the opportunity for dynamic interaction during airway management. ${ }^{3}$

Currently, several types of video laryngoscopes are available each with different blade shapes, user interface, and geometry and tube insertion strategy. ${ }^{4}$ King Vision Video Laryngoscope (KVVL) is an hyperangulated optical laryngoscope that provides a view of the glottis without alignment of the oral, pharyngeal, and tracheal axes.
${ }^{1-3}$ Department of Anesthesia, HBT Medical College and Dr RN Cooper Hospital, Mumbai, Maharashtra, India

Corresponding Author: Pratika P Bhokare, Department of Anesthesia, HBT Medical College and Dr RN Cooper Hospital, Mumbai, Maharashtra, India, Phone: +91 9820293359, e-mail: Pratika16691@gmail.com

How to cite this article: Sonavane SR, Gvalani SK, Bhokare PP. Comparison between Conventional Macintosh Laryngoscope and King Vision Video Laryngoscope in Endotracheal Intubation for Elective Surgeries: A Prospective Randomized Study. Res Inno in Anesth 2020; 5(2):28-32.

Source of support: Nil

Conflict of interest: None

In our study, we have used KVVL for tracheal intubation and compared its efficacy, ease, safety, and shorter learning curve with that of the conventional Macintosh direct laryngoscope. The laryngoscopy view, hemodynamic response, and the attempts and time of endotracheal intubation of both Macintosh and KVVL have been compared in this prospective randomized study. 
Several studies comparing the mentioned methods of intubation in manikins are available. However, not many studies have been conducted which compare the Macintosh with KVVL in a large subject pool.

\section{Materials and Methods}

This is a prospective, randomized study conducted from August 2017 for a period of 1 year after approval was obtained from the Institutional Ethics Committee. This study was carried out in 200 patients fulfilling the inclusion criteria and belonging to either sex within the age group of $18-60$ years.

\section{Sample Size}

A total of 200 patients with 100 patients in each group I and II.

\section{Inclusion Criteria}

- Patients with age 18-60 years, posted for elective surgeries under GA.

- Patients with ASA grade I and II.

- Patients with inter-incisor distance $>5 \mathrm{~cm}$.

- Patients with MPC I and II.

- Patients with thyromental distance $>6.5 \mathrm{~cm}$.

\section{Exclusion Criteria}

- Patients posted for emergency surgeries.

- Patients with ASA grade III and IV.

- Patients with MPC III and IV.

- Patients with an anticipated difficult airway.

- Pregnant patients.

Modified Cormack-Lehane's Grading of Direct Laryngoscopy

\begin{tabular}{ll}
\hline Grades & \\
\hline I & Visualization of entire vocal cords. \\
II a & Visualization of the posterior part of vocal cords. \\
II b & Visualization of arytenoids only. \\
III a & Epiglottis liftable. \\
III b & Epiglottis adherent or only tip visible. \\
IV & No glottic structures were seen. \\
\hline
\end{tabular}

\section{Methods}

After obtaining Institutional Ethics Committee approval, all patients were explained about the nature of the study, and a written informed valid consent on a separate consent form was taken from the patient and his/her relative.

A detailed preanesthetic check-up was done before surgery. History of chief complaints, any systemic medical disease, any previous surgery and anesthesia administration, any addiction, history of any drug intake, or any drug allergy was noted. Along with routine general and systemic examination, a thorough airway assessment was carried out. Airway assessment included mouth opening, MPC grading, and measurement of thyromental distance. Routine preoperative investigations including complete hemogram and liver and renal functions, chest X-ray, and electrocardiogram (ECG) were obtained.
Patients were divided into the following two groups using the computer-generated randomization method.

Group I-Patients receiving general anesthesia with endotracheal intubation using a conventional Macintosh blade.

Group II-Patients receiving general anesthesia with endotracheal intubation using KVVL.

On the day of surgery, the NBM status of the patient was confirmed and consent was taken. After taking the patients on the operating table, the standard monitors including ECG, noninvasive blood pressure (NIBP), and pulse oximeter were attached and the readings of vital parameters of the patients were noted.

Patients were made to lie in a supine position on the operating table with their heads resting on a surgical head ring. The patients were pre-oxygenated for 3 minutes with an anatomical face mask on a closed circuit. Patients were then pre-medicated with Inj. glycopyrrolate $4 \mu \mathrm{g} / \mathrm{kg}$, Inj. midazolam $0.03 \mathrm{mg} / \mathrm{kg}$, and Inj. fentanyl $2 \mu \mathrm{g} / \mathrm{kg}$. Anesthesia induction was done with $\mathrm{Inj}$. propofol $2 \mathrm{mg} / \mathrm{kg}$. Post-induction, baseline readings of hemodynamic parameters, i.e., heart rate, mean arterial pressure (MAP), and (peripheral oxygen saturation) $\mathrm{SpO}_{2}$ were taken. Inj. rocuronium was given as a muscle relaxant of choice. Orotracheal intubation was performed using the allocated intubation device for each group, after 60 seconds. Before laryngoscopy and 60 seconds after injecting rocuronium, second reading of hemodynamic parameters was taken. Immediately after intubation and confirmation of endotracheal tube placement, the next reading of hemodynamic parameters was taken. Inhalational agent isoflurane was given with a constant $1 \%$ dial concentration for 10 minutes for all the patients and the final reading of hemodynamic parameters was taken at the end of 10 minutes.

The parameters studied were laryngoscopy view (using modified Cormack-Lehane scoring system), assessment of laryngoscopy and intubation procedure (number of attempts for successful intubation), maneuvers used (BURP—Backward, Upward, Rightward and Posterior External Laryngeal Pressure) during laryngoscopy, endotracheal tube insertion time, and hemodynamic response (heart rate, mean arterial blood pressure, and $\mathrm{SpO}_{2}$ ).

\section{Statistical Analysis}

The statistical analysis of the data from the study was performed with GraphPad Instat V3.4 and Microsoft Office Excel 2007. The continuous data are expressed as mean (standard deviation). The categorical data are summarized as percentages. The continuous variables are analyzed by the unpaired $t$-test and Fischer's exact test is used for the analysis of contingency tables. Categorical data are analyzed using the Chi-square test. $p$ values $<0.05$ are accepted as indicative of statistical significance.

\section{RESULTS}

Data from 200 patients were analyzed. No intubation failure occurred in the study.

\section{Mean Age}

The mean age in group I was 39.2 years and in group II was 37.08 years. The age in both groups was comparable and not statistically significant ( $p$ value-0.1538) (Table 1).

Table 1: Mean age

\begin{tabular}{|c|c|c|c|c|c|}
\hline \multirow[b]{2}{*}{ Parameter } & \multicolumn{2}{|c|}{ Group I } & \multicolumn{2}{|c|}{ Group II } & \multirow[b]{2}{*}{$p$ value } \\
\hline & Mean & $S D$ & Mean & $S D$ & \\
\hline Age (in years) & 39.2 & 11.16 & 37.08 & 9.73 & 0.1538 \\
\hline
\end{tabular}




\section{Gender Distribution}

The difference between female and male patients in both groups was not statistically significant ( $p$ value -0.3220 ) (Table 2 ).

\section{MPC Grading}

The difference in MPC grading in both groups was not statistically significant ( $p$ value-0.1897) (Table 3).

\section{Cormack-Lehane (CL) Grade}

In group I, out of 100 patients who were intubated with Macintosh laryngoscope, 35 had grade I Cormack-Lehane grade, 33 had grade II a, 26 had grade II b, and 6 had grade III a glottic view.

In group II, out of 100 patients who were intubated with KVVL, 64 had grade I CL view, 30 had grade II a, and 6 had grade II b glottic view.

There was a statistically significant difference between both groups ( $p$ value $<0.0001$ ) (Table 4).

\section{Number of Attempts at Intubation}

The difference in intubation attempts in both groups was not statistically significant ( $p$ value -0.4448 ) (Table 5).

Table 2: Gender distribution

\begin{tabular}{lllll}
\hline & Group I & & Group II & \\
\cline { 2 - 2 } Gender & $(\%)$ & & (\%) & p value \\
\hline Male & 55 & 48 & 0.3220 \\
Female & 45 & 52 & \\
\hline
\end{tabular}

Table 3: MPC grading

\begin{tabular}{lllll}
\hline & Group I & & Group II & \\
\cline { 2 - 2 } MPC grade & $(\%)$ & & (\%) & pvalue \\
\hline I & 33 & 43 & 0.1897 \\
II & 67 & 57 & \\
\hline
\end{tabular}

Table 4: Cormack-Lehane $(\mathrm{CL})$ grade

\begin{tabular}{lllll}
\hline & Group I & Group II & \\
\cline { 2 - 2 } CL grade & $(\%)$ & & (\%) & p value \\
\hline I & 35 & 64 & $<0.0001$ \\
II a & 33 & 30 & \\
II b & 26 & 6 & \\
III a & 6 & 0 & \\
\hline
\end{tabular}

Table 5: Number of attempts at intubation

\begin{tabular}{|c|c|c|c|}
\hline \multirow{2}{*}{$\begin{array}{l}\text { No. of } \\
\text { attempts }\end{array}$} & Group I & Group II & \multirow[b]{2}{*}{$p$ value } \\
\hline & (\%) & (\%) & \\
\hline 1 & 95 & 98 & 0.4448 \\
\hline 2 & 5 & 2 & \\
\hline
\end{tabular}

Table 6: Optimization maneuver used

\begin{tabular}{lllll}
\hline $\begin{array}{l}\text { BURP used as } \\
\text { a maneuver }\end{array}$ & Group I & & Group II & \\
\cline { 2 - 2 } & $(\%)$ & & (\%) & pvalue \\
\hline Yes & 58 & 22 & $<0.0001$ \\
No & 42 & 78 & \\
\hline
\end{tabular}

\section{Optimization Maneuver Used}

Out of 100 patients in group I, 58 patients required optimization maneuvers (BURP) while only 22 patients required the same in group II. The difference in both groups was statistically significant ( $p$ value $<0.0001$ ) (Table 6)

\section{ET Tube Insertion Time}

The mean time for ET tube insertion in group I was 17.47 seconds, whereas, in group II, it was 14.87 seconds, the difference being statistically significant ( $p$ value $<0.0001$ ) (Table 7).

\section{Hemodynamic Parameters at Baseline (after Induction)}

The mean heart rate in group I was 81.12 and group II was 81.13 with no statistical significance ( $p$ value-0.9895).

The MAP in group I was 76.61 and group II was 75.61 with no statistical significance ( $p$ value-0.1754).

The $\mathrm{SpO}_{2}$ in both groups was the same (99\%) (Table 8).

\section{Hemodynamic Parameters before Laryngoscopy}

The mean heart rate in group I was 74.62 and group II was 73.39 with no statistical significance ( $p$ value-0.0908).

The MAP in group I was 71.24 and group II was 70.00 with no statistical significance ( $p$ value-0.0776).

The $\mathrm{SpO}_{2}$ in both groups was the same (99\%) (Table 9).

\section{Hemodynamic Parameters Immediately after Intubation}

The mean heart rate in group I was 93.88 and group II was 85.52. The difference in both groups was statistically significant ( $p$ value $<0.0001)$

The MAP in group I was 87.76 and group II was 78.97. The difference in both groups was statistically significant ( $p$ value $<$ 0.0001) (Table 10).

The $\mathrm{SpO}_{2}$ in both groups was the same (99\%).

Table 7: ET tube insertion time

\begin{tabular}{lllll}
\hline & Group I & & Group II & \\
\cline { 2 - 2 } Parameter & Mean & & Mean & p value \\
\hline $\begin{array}{l}\text { ET tube } \\
\text { insertion time }\end{array}$ & 17.46 & 14.87 & $<0.0001$ \\
\hline
\end{tabular}

Table 8: Hemodynamic parameters at baseline (after induction)

\begin{tabular}{|c|c|c|c|}
\hline \multirow{2}{*}{$\begin{array}{l}\text { Hemodynamic } \\
\text { parameters }\end{array}$} & Group I & Group II & \multirow[b]{2}{*}{$p$ value } \\
\hline & Mean & Mean & \\
\hline $\begin{array}{l}\text { HR (beats/ } \\
\text { minute) }\end{array}$ & 81.12 & 81.13 & 0.9895 \\
\hline MAP (mm Hg) & 76.61 & 75.61 & 0.1754 \\
\hline $\mathrm{SpO}_{2}(\%)$ & 99 & 99 & - \\
\hline
\end{tabular}

Table 9: Hemodynamic parameters before laryngoscopy

\begin{tabular}{|c|c|c|c|}
\hline \multirow{2}{*}{$\begin{array}{l}\text { Hemodynamic } \\
\text { parameters }\end{array}$} & Group I & Group II & \multirow[b]{2}{*}{$p$ value } \\
\hline & Mean & Mean & \\
\hline $\begin{array}{l}\text { HR (beats/ } \\
\text { minute) }\end{array}$ & 74.62 & 73.39 & 0.0908 \\
\hline MAP $(\mathrm{mm} \mathrm{Hg})$ & 71.24 & 70.00 & 0.0776 \\
\hline $\mathrm{SpO}_{2}(\%)$ & 99 & 99 & - \\
\hline
\end{tabular}


Table 10: Hemodynamic parameters immediately after intubation

\begin{tabular}{|c|c|c|c|}
\hline \multirow{2}{*}{$\begin{array}{l}\text { Hemodynamic } \\
\text { parameters }\end{array}$} & Group I & Group II & \multirow[b]{2}{*}{$p$ value } \\
\hline & Mean & Mean & \\
\hline $\begin{array}{l}\mathrm{HR} \text { (beats/ } \\
\text { minute) }\end{array}$ & 93.88 & 85.52 & $<0.0001$ \\
\hline MAP (mm Hg) & 87.76 & 78.97 & $<0.0001$ \\
\hline $\mathrm{SpO}_{2}(\%)$ & 99 & 99 & - \\
\hline
\end{tabular}

Table 11: Hemodynamic parameters 10 minutes after intubation

\begin{tabular}{lllll}
\hline $\begin{array}{l}\text { Hemodynamic } \\
\text { parameters }\end{array}$ & Group I & & Group II & \\
\cline { 2 - 2 } $\begin{array}{l}\text { HR (beats/ } \\
\text { minute) }\end{array}$ & 85.09 & & Mean & p value \\
\hline $\mathrm{MAP}(\mathrm{mm} \mathrm{Hg})$ & 81.57 & & 77.71 & $<0.0001$ \\
$\mathrm{SpO}_{2}(\%)$ & 99 & 73.45 & $<0.0001$ \\
\hline
\end{tabular}

Hemodynamic Parameters 10 Minutes after Intubation

The mean heart rate in group I was 85.09 and group II was 77.71. The difference in both groups was statistically significant ( $p$ value $<0.0001)$.

The MAP in group I was 81.57 and group II was 73.45 . The difference in both groups was statistically significant ( $p$ value $<$ 0.0001)

The $\mathrm{SpO}_{2}$ in both groups was the same (99\%) (Table 11).

\section{Discussion}

Securing the airway is one of the most common interventions performed by anesthesiologists. Direct laryngoscopy has been the standard technique for tracheal intubation, despite rapid increments in medical technology.

Although laryngoscopes were invented in the early 19th century, tracheal intubation under direct vision was greatly facilitated by the development of a special curved laryngoscope blade introduced by Macintosh in $1943 .{ }^{5}$ The conventional direct laryngoscopes have been associated with failure to provide an adequate view of the glottic region. As a result, alternative intubation devices with video, optical, or fiber-optic imaging have emerged. Video laryngoscopes provide high-quality visual images that can be enlarged on a monitor for easier visualization. With a channeled blade, it becomes easier to intubate. Intubation can even be done in patients with the head in a neutral position and the entire operating room can visualize the progress in real time. ${ }^{6}$

Hemodynamic changes to laryngoscopy and endotracheal intubation involve intense sympathetic discharge caused by stimulation of epipharynx and laryngopharynx. This pressor response to endotracheal intubation is a cause of special concern for the anesthesiologist.

Our study compared the efficacy of laryngoscopy using the conventional Macintosh blade, with laryngoscopy using the KVVL with regards to laryngoscopic view and hemodynamic parameters.

The differences in the patients divided into both groups I and II were not significant statistically with respect to age, gender, and MPC grading. In our study, in group I, 35 had grade I CL glottic view, 33 had grade lla, 26 had grade llb, and 6 had grade Illa glottic view. In group II, out of 100 patients who were intubated with KVVL, 64 had grade I CL view, 30 had grade II a, and 6 had grade II b glottic view.
There was a statistically significant difference between both groups ( $p$ value $<0.0001$ ). Thus, we found that the KVVL improves the laryngoscopic view achieving a better glottic visualization.

Garhwal et al. in $2016^{7}$ compared glottic view with Macintosh blade, Miller blade with KVVL in patients posted for elective surgeries. Their study supports the superior performance of KVVL for glottic visualization.

Murphy et al. in $2014^{8}$ compared the KVVL to Macintosh DL in simulated normal and difficult airways and concluded that KVVL improves the laryngoscopic view achieving a better glottic view.

There was no significant difference found with regards to the number of intubation trials between both groups.

In our study, there was a significant difference in the need for optimization maneuvers among the two groups. King Vision Video Laryngoscope required less optimization maneuvers such as BURP. Also, the ET tube insertion time was significantly less and much faster with KVVL than with Macintosh.

In 2016, Elhadi et al. $^{9}$ compared the need for optimization maneuvers such as BURP required for visualization of glottis using Macintosh direct laryngoscopy and KVVL. They found that KVVL required less need for optimization maneuvers. However, the study showed that there was no significant difference in mean tube insertion time between both groups.

Our study showed successful intubation attempts in both the groups irrespective of the laryngoscope used.

Although no significant difference was found in the baseline heart rate and the heart rate before laryngoscopy in both the groups of our study, there was a significant difference in the heart rate immediately after laryngoscopy and 10 minutes after intubation in both the groups with $p$ value $<0.0001$. Similarly, the baseline MAP and the MAP before laryngoscopy in both the groups had no significant difference. There was, however, a significant difference in the MAP immediately after laryngoscopy and 10 minutes after intubation in both the groups with a $p$ value $<0.0001$.

In 2017, Mogahed et al. ${ }^{10}$ compared the efficacy of intubation with Macintosh, C-MACD blade, and KVVL in controlled hypertensive patients. They compared heart rate, $\mathrm{MAP}, \mathrm{SpO}_{2}$, and $\mathrm{EtCO}_{2}$ in three groups. They observed that there was a statistically significant difference in the heart rate and MAP between the Macintosh group on one side, with no significant difference between the C-MAC D blade and the KVVL group.

The mean $\mathrm{SpO}_{2}$ was maintained (99\%) in both the Macintosh and KVVL groups throughout the procedure.

The current trend in the rise in popularity of video laryngoscope may necessitate a change in the algorithm for difficult airway management and may make the use of video laryngoscope, the first line of approach for endotracheal intubation. There is, however, a concern that the teaching of difficult airway approaches may be affected adversely. Currently, no evidence indicates that the use of a video laryngoscope reduces the number of intubation attempts or the incidence of hypoxia or respiratory complications. ${ }^{11}$

The litigation related to adverse outcomes in a difficult airway scenario has decreased in recent times in the USA due to the development of safer techniques and devices for endotracheal intubation, of which one such device is the video laryngoscope. In our country, a rising trend in litigation has been noted over the past decade. Safe management of a difficult airway is of prime concern to the anesthetist to ensure patient well-being and prevent litigation. 


\section{Conclusion}

From our study of comparison between Macintosh and KVVL, we conclude that the KVVL has been found out to be more effective in reducing hemodynamic response to laryngoscopy and intubation. King Vision Video Laryngoscope was associated with a better laryngoscopic view, significantly less intubation time, and less usage of optimization maneuvers (BURP) during endotracheal intubation.

Safe management of a difficult airway is of prime concern to the anesthetist to ensure patient safety and prevent litigation. A device such as a video laryngoscope that ensures safer and faster intubation can only gain popularity in the future.

\section{Clinical Significance}

This study aims at providing evidence to guide the anesthesiologists regarding the merits and demerits of video laryngoscopes and aid them in safer airway management techniques without complications.

\section{References}

1. Levitan RM, Heitz JW, Sweeney M, et al. The complexities of tracheal intubation with direct laryngoscopy and alternative intubation devices. Ann Emerg Med 2011;57(3):240-247. DOI: 10.1016/j. annemergmed.2010.05.035.

2. Lee LC. Two curves theory does not clearly explain laryngoscopy and intubation. Br J Anaesth 2011;106(6):909-910. author reply 910-1 10.1093/bja/aer137.
3. Dorsch JA, Dorsch SE. Understanding Anesthesia Equipment. 5th ed. 2012.

4. Paolini JB, Donati F, Drolet P. Review article:video-laryngoscopy: another tool for difficult intubation or a new paradigm in airway management? Can J Anaesth 2013;60(2):184-191. DOI: 10.1007/s12630-012-9859-5.

5. Unzueta MC, Ignacio Casas J, Merten A. Macintosh's laryngoscope. Anesthesiology 2005;102(1):242. DOI: 10.1097/00000542-20050100000046.

6. Chemsian R, Bhananker S, Ramaiah R. Videolaryngoscopy. Int J Crit Illn Inj Sci 2014;4(1):35-41. DOI: 10.4103/2229-5151.12801.

7. Garhwal $A M$, Bhure AR, Bhargava SR, et al. A clinical assessment of Macintosh blade, Miller blade and King Vision TM Videolaryngoscope for laryngeal aexposure and difficulty in endotracheal exposure. J Evidence Based Med Healthcare 2016;3(31):1380.

8. Murphy LD, Kovacs GJ, Reardon PM, et al. Comparison of the king vision video laryngoscope with the macintosh laryngoscope.J Emerg Med 2014;47(2):239-246. DOI: 10.1016/j.jemermed.2014.02.008.

9. Elhadi SM, Rady WK, Elfadly AM. A comparative study between the macintosh laryngoscope and the king vision video laryngoscope in endotracheal intubation. Res Opin Anesth Intensive Care 2016;3(4):168-172. DOI: 10.4103/2356-9115.195881.

10. Mogahed MM, Elghamri MR, Anwar AG. Comparative study of intubation performance between macintosh, the channeled king vision and the C-MAC D-blade videolaryngoscope in controlled hypertensive patients. J Anesth Clin Res 2017;8(11):780. DOI: 10.4172/2155-6148.1000780.

11. Lewis SR, Butler AR, Parker J, et al. Videolaryngoscopy versus direct laryngoscopy for adult patients requiring tracheal intubation. Cochrane Database Syst Rev 2016;11(11):CD011136. DOI: 10.1002/14651858.CD011136.pub2. 